\title{
Enzymatic Synthesis of the Flavone Glucosides, Prunin and Isoquercetin, and the Aglycones, Naringenin and Quercetin, with Selective $\alpha$-L-Rhamnosidase and $\beta$-D-Glucosidase Activities of Naringinase
}

\author{
Hélder Vila-Real, ${ }^{1}$ António J. Alfaia, ${ }^{1}$ M. Rosário Bronze, ${ }^{1,2}$ António R. T. Calado, ${ }^{1}$ \\ and Maria H. L. Ribeiro ${ }^{1}$ \\ ${ }^{1}$ Research Institute for Medicines and Pharmaceutical Sciences (i-Med-UL), Faculty of Pharmacy, University of Lisbon, \\ Avenue Prof. Gama Pinto, 1649-003 Lisbon, Portugal \\ ${ }^{2}$ Departmento de Química, Instituto de Tecnologia Química e Biológica, Apartado 127, Av. República, 2784-505 Oeiras, Portugal \\ Correspondence should be addressed to Maria H. L. Ribeiro, mhribeiro@ff.ul.pt
}

Received 21 April 2011; Accepted 8 July 2011

Academic Editor: J. Guisan

Copyright ( $\odot 2011$ Hélder Vila-Real et al. This is an open access article distributed under the Creative Commons Attribution License, which permits unrestricted use, distribution, and reproduction in any medium, provided the original work is properly cited.

\begin{abstract}
The production of flavonoid glycosides by removing rhamnose from rutinosides can be accomplished through enzymatic catalysis. Naringinase is an enzyme complex, expressing both $\alpha$-L-rhamnosidase and $\beta$-D-glucosidase activities, with application in glycosides hydrolysis. To produce monoglycosylated flavonoids with naringinase, the expression of $\beta$-D-glucosidase activity is not desirable leading to the need of expensive methods for $\alpha$-L-rhamnosidase purification. Therefore, the main purpose of this study was the inactivation of $\beta$-D-glucosidase activity expressed by naringinase keeping $\alpha$-L-rhamnosidase with a high retention activity. Response surface methodology (RSM) was used to evaluate the effects of temperature and $\mathrm{pH}$ on $\beta$ - $\mathrm{D}$-glucosidase inactivation. A selective inactivation of $\beta$-D-glucosidase activity of naringinase was achieved at $81.5^{\circ} \mathrm{C}$ and $\mathrm{pH} 3.9$, keeping a very high residual activity of $\alpha$-L-rhamnosidase (78\%). This was a crucial achievement towards an easy and cheap production method of very expensive flavonoids, like prunin and isoquercetin starting from naringin and rutin, respectively.
\end{abstract}

\section{Introduction}

The production of monoglycosylated flavonoids is an interesting application field of enzymatic biocatalysis by removing the rhamnose radical, namely, of rutinosides, as well as in the production of rhamnose itself. The deglycosylation of flavonoids can improve biological activity through its bioavailability improvement [1]. Such improvement may be related not only to pharmacokinetics and pharmacodynamics, but also, to the overall molecule structure. This result supports that monoglycosylated flavonoids and its aglycones are more easily absorbed, than the original lead compound. Flavonoids show a wide range of beneficial effects on human health, including cardiovascular and chronic diseases and certain forms of cancer activity [2-4], as well as antimicrobial, antioxidant, antiviral, antiplatelet, anti-ischemic, antitumor, anti-inflammatory, antiallergic, estrogenic, and radical-scavenging activities $[5,6]$.

Quercetin, isoquercetin, and other flavonoids have been shown to modify eicosanoid biosynthesis (antiprostanoid and anti-inflammatory responses), protect low-density lipoprotein from oxidation (prevent atherosclerotic plaque formation), prevent platelet aggregation (antithrombic effects), and promote relaxation of cardiovascular smooth muscle (antihypertensive, antiarrhythmic effects) [6]. Most beneficial health effects of quercetin are related to absorption, metabolism, and bioavailability into the human body. In addition, flavonoids, like prunin, have been shown to have antiviral properties [5]. The activity of flavonoids as inhibitors of reverse transcriptase suggests a place for these compounds in the control of retrovirus infections, such as acquired immunodeficiency syndrome. Moreover, to 
specific effects the broad-modulating effects of flavonoids can serve as starting material for drug development. Due to these numerous properties and applications, flavonoids have gained growing interest.

Conventional chemical methods for the preparation of flavonoids and saponins usually produce side reactions. In this context enzymatic modification is advantageous due to selectivity and mildness of the reaction conditions.

Naringinase is an enzyme complex used in compounds deglycosylation and with a high potential in food and pharmaceutical industries. Naringinase provides both $\alpha$-Lrhamnosidase and $\beta$-D-glucosidase activities (Figure 1) and has been used to accomplish some glycosides hydrolysis [79].

Statistical design of experiments is a useful tool to provide experimental schemes where the parameters (factors) under study are combined at different levels to determine the influence of a particular factor on the response. Additionally, an adequate experimental design not only allows the determination of individual effects but also the interactions between them can be uncovered.

Response surface methodology (RSM) is an efficient statistical technique for the modelling and optimization of multiple variables in order to predict the best performance conditions with a minimum number of experiments [10]. It consists of a group of mathematical and statistical procedures that can be used to study relationships between one or more responses and a number of independent variables. RSM defines the effect of the independent variables, alone or in combination, on the process. In addition, to analyze the effects of the independent variables, this experimental methodology generates a mathematical model that may accurately describe the overall process. These methods find major importance when the effect of one variable is affected by the setting of another. Such "interaction effects" between variables are difficult to detect by a traditional experimental setup where one variable is changed at a time. The coefficients of the mathematical model (usually a polynomial equation) representing the variations of the experimental response of interest may be evaluated with high precision. Additionally, RSM has the advantage of being less expensive and time consuming than the classical methods [11].

RSM is a nonconventional approach that has been successfully used for the optimization of enzymatic reactions conditions [11-13], medium composition [14, 15]. In this work, central composite rotatable design (CCRD) and RSM were used to compare the combined effects of temperature and $\mathrm{pH}$ on $\beta$-D-glucosidase activity of naringinase.

To produce monoglycosylated flavonoids with naringinase, the presence of $\beta$-D-glucosidase activity expression leads to the need of using selective inhibitors or even expensive methods of $\alpha$-L-rhamnosidase purification [16]. In the current study the effect of $\mathrm{pH}$ and temperature on $\beta$ $\mathrm{D}$-glucosidase inactivation from naringinase were evaluated using a central composite face-centered design. It was possible to define the best factor combination of $\beta$-D-glucosidase inactivation from naringinase, keeping $\alpha$-L-rhamnosidase expression in a high activity. This naringinase with inactivated $\beta$-D-glucosidase and expressing $\alpha$-L-rhamnosidase allowed the production of two very expensive flavonoid glucosides, prunin and isoquercetin, in an easy and cheap bioprocess starting from naringin and rutin, respectively.

\section{Materials and Methods}

2.1. Chemicals and Enzyme. p-Nitrophenyl $\alpha$-L-rhamnopyranoside (4-NRP) and $p$-nitrophenyl $\beta$-D-glucopyranoside (4-NGP) were from Sigma-Aldrich. All other chemicals were of reagent grade and were obtained from various sources.

Naringinase (CAS no. 9068-31-9, cat. no. 1385) from Penicillium decumbens was obtained from Sigma-Aldrich and stored at $-20^{\circ} \mathrm{C}$. The lyophilized naringinase powder was dissolved in the appropriate buffer solution 24 hours before experiments and was kept at $4^{\circ} \mathrm{C}$.

2.2. Analytical Methods. The concentration of $p$-nitrophenol produced after the hydrolysis of 4-NRP and 4-NGP was evaluated spectrophotometrically (Zenith 3100 spectrofluorimeter) at $\lambda=340 \mathrm{~nm}$, using a calibration curve of each compound.

The flavonoid rutinosides, glucosides, and aglycones were eluted running a TLC on an RP-18 silica-gel plate with methanol-water-acetic acid (50/44/6, v/v/v) [17]. The spot visualization was evaluated under UV light at $254 \mathrm{~nm}$ followed by spraying with a freshly prepared solution of acetic acid/sulphuric acid concentrated $/ p$-anisaldehyde $(100 / 2 / 1, \mathrm{v} / \mathrm{v} / \mathrm{v})$ heated at $150^{\circ} \mathrm{C}$ for $5 \mathrm{~min}[18]$.

The HPLC-DAD-ESI-MS/MS experiments used to identify the produced compounds (prunin, naringenin, isoquercetin, and quercetin) were performed with a liquid chromatograph (Alliance, Waters 2695 Separation Module) system with a photodiode array detector (DAD, Waters 2996) set at $280 \mathrm{~nm}$ (for monitoring) in tandem with a mass spectrometer (Micromass Quattro Micro API) with a Triple Quadrupole (TQ) and an electrospray ion source (ESI) operating in negative mode. Chromatographic conditions were as follows: column C18 (Synergi, Phenomenex) $100 \mathrm{~mm}$ $\times 2.0 \mathrm{~mm}, 2.5 \mu \mathrm{m}$; eluent (A) water-formic acid (99.5:0.5, $\mathrm{v} / \mathrm{v}$ ), (B) acetonitrile (LC-MS grade, Merck). The linear gradient was at initial time $95 \%$ eluent $\mathrm{A}$, and at $30 \mathrm{~min}$ $60 \%$ eluent $\mathrm{A}$, at $45 \mathrm{~min} 10 \%$ eluent $\mathrm{A}$. The flow rate was $0.25 \mathrm{~mL} / \mathrm{min}$ and the column temperature $35^{\circ} \mathrm{C}$. Mass range was measured from 100-1000 amu. The ESI source conditions were adjusted as follows: source capillary operating at $2.5 \mathrm{kV}$ and the extraction cone at $30 \mathrm{~V}$; the source temperature was $150^{\circ} \mathrm{C}$ and the desolvation temperature was $350^{\circ} \mathrm{C}$.

2.3. Activity Measurement. The activity of $\alpha$-L-rhamnosidase expressed by naringinase was evaluated using $0.20 \mathrm{mM}$ of 4 NRP in $20 \mathrm{mM}$ citrate buffer at $\mathrm{pH} 3.4$, while the activity of expressed $\beta$-D-glucosidase was determined using $0.20 \mathrm{mM} 4$ $\mathrm{NGP}$ in $20 \mathrm{mM}$ citrate buffer at $\mathrm{pH}$ 3.4. A naringinase concentration of $50 \mathrm{mg} \mathrm{L}^{-1}$ was used in these experiments. The enzymatic hydrolysis was followed spectrophotometrically. The absorption was measured every $1 \mathrm{~min}$ during $30 \mathrm{~min}$, at $30.0^{\circ} \mathrm{C}$. In both reactions $1 \mathrm{~mol}$ of substrate led to $1 \mathrm{~mol}$ 


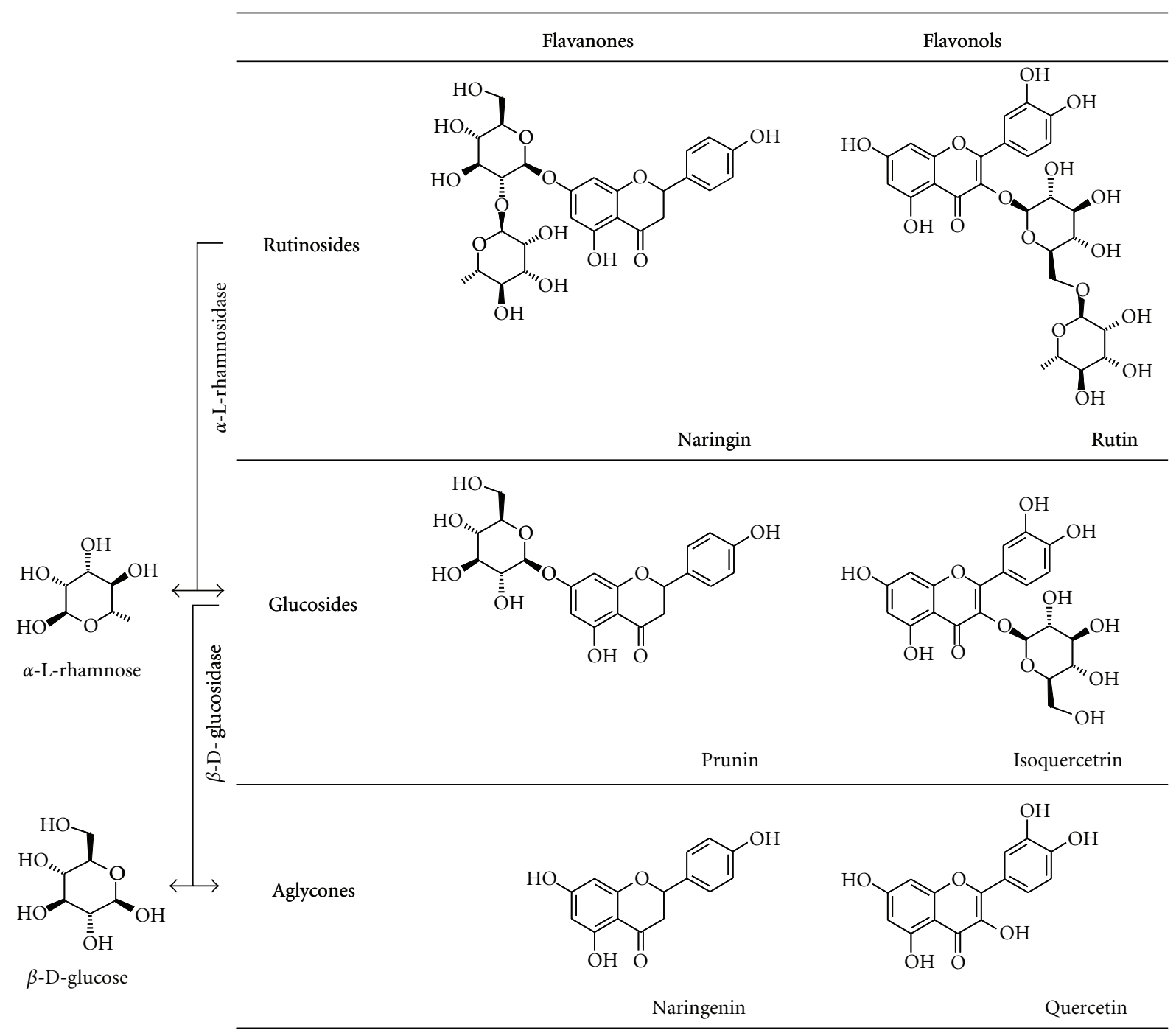

FIGURE 1: Scheme of the production of flavonoid glucosides and aglycones starting from its rutinosides precursors using an enzymatic approach ( $\alpha$-L-rhamnosidase and $\beta$-D-glucosidase activities of naringinase).

of product. A calibration curve was built for each substrate and respective product. The enzyme activity $(A)$ of $\alpha$-Lrhamnosidase and $\beta$-D-glucosidase activities of naringinase was calculated by linear regression on the first data-points during the initial $30 \mathrm{~min}$ reaction time.

2.4. $\mathrm{pH}$ Profile. The influence of $\mathrm{pH}$ on $\beta$-D-glucosidase and $\alpha$-L-rhamnosidase specific activity $(A)$ can be described by

$$
A=\frac{A_{\max }}{1+10^{\mathrm{p} K_{1}-\mathrm{pH}}+10^{\mathrm{pH}-\mathrm{p} K_{2}}},
$$

where $A_{\max }$ is the maximal enzyme-specific activity and $K_{1}$, $K_{2}$ are the equilibrium constants of enzyme deprotonation $[19,20]$.

The naringinase activity $\mathrm{pH}$ profiles were obtained through nonlinear regression by minimising the residual sum of squares between the experimental data points of the specific activity versus $\mathrm{pH}$ and those estimated by the model, using Solver add-in from Microsoft Excel 2003 for
Windows XP and considering the following options: Newton method; 100 iterations, precision of $10^{-6}, 5 \%$ of tolerance, and $10^{-4}$ convergence. The experimental optimum $\mathrm{pH}$ values were used as initial parameters of the nonlinear regression, and no constraints were used. Optimum $\mathrm{pH}$ values were then determined from the zero calculation of (1) first derivative.

2.5. Inactivation Kinetics. In order to study $\beta$-D-glucosidase and $\alpha$-L-rhamnosidase inactivation kinetics, a temperature range of $75-85^{\circ} \mathrm{C}$ and a $\mathrm{pH}$ range of 3.19-6.01 were used. Naringinase thermal inactivation was carried out in Eppendorf tubes $(1.5 \mathrm{~mL})$, at isothermal conditions $\left( \pm 0.1^{\circ} \mathrm{C}\right)$ using a thermostatic water bath (Julabo Hc/F18). The inactivation time ranged from 2.5 to $160 \mathrm{~min}$ according to the temperature used. Inactivation was stopped by removing the enzyme samples to an ice water bath for $5 \mathrm{~min}$. Enzyme activity was measured, in triplicate, immediately as well as one day after thermal inactivation, without occurring reactivation. $A_{0}$ was 
TABLE 1: Coded and decoded levels of the experimental factors used in experimental design.

\begin{tabular}{lcc}
\hline CCRD & $\mathrm{pH}$ & Temperature $\left({ }^{\circ} \mathrm{C}\right)$ \\
\hline$-\sqrt{ } 2$ & 3.2 & 75.0 \\
-1 & 3.6 & 76.5 \\
0 & 4.6 & 80.0 \\
+1 & 5.6 & 83.5 \\
$+\sqrt{ } 2$ & 6.0 & 85.0 \\
\hline
\end{tabular}

the activity of the control, that is, the enzyme sample without being submitted to inactivation.

First-order inactivation rate constants and $\alpha_{1}$ parameter were determined by nonlinear regression minimising the residual sum of squares between the experimental data points of the residual activity versus time and those estimated by the model, using Solver add-in from Microsoft Excel 2003 for Windows XP, considering the following options: Newton method; 100 iterations, precision of $10^{-6}, 5 \%$ tolerance, and $1 \times 10^{-4}$ convergence. The first-order deactivation rate constant obtained form linear regression of $\ln A_{r}$ versus $t$ was used as the initial values for the nonlinear regression $k_{1}$ parameter. The nonlinear regression parameters were restricted to positive numbers, and also $\alpha_{1}$ was restricted to the gap between 0 and 1 .

The time needed to achieve a specific activity of $\beta$-D-glucosidase $0.01 \%$ of the specific activity of $\alpha$-Lrhamnosidase was $t_{0.01 \%}$. At these time $\left(t_{0.01 \%}\right)$ the $\beta$-Dglucosidase was considered completely inactivated. The $t$ values were determined through extrapolation of the kinetic inactivation profiles obtained under different conditions of $\mathrm{pH}$ and temperature. The relative activity of $\alpha$-Lrhamnosidase at this time values $(t)$ was determined for each specific condition of $\mathrm{pH}$ and temperature.

2.6. Experimental Design. The optimized temperature and $\mathrm{pH}$ inactivation conditions of $\beta$-D-glucosidase activity of naringinase were established via Response Surface Methodology (RSM). Using this methodology two variables were tested simultaneously with a minimum number of trials, according to adequate experimental designs, which enables to find interactions between variables [21]. The experimental design methodology makes use of statistical tools for selecting a minimum set of experiments adequately distributed in the experimental region (experimental matrix).

In this study, $\beta$-D-glucosidase inactivation was carried out following a central composite rotatable design (CCRD). For the design setup, three different coded levels for each factor were used, low $(-1)$, center (0), and high $(+1)$, as indicated in Table 1 . The response variables were $\beta$-D-glucosidase and $\alpha$-L-rhamnosidase activities $\left(\mathrm{mg} \mathrm{mL}^{-1} \mathrm{~min}^{-1}\right)$. The experiments were performed in random order. Triplicate experiments were carried out at all design points.

The choice of experimental domains resulted from preliminary studies. The hydrolysis was carried out in $20 \mathrm{mM}$ citrate buffer. A total of 11 experiments were carried out in each CCRD: four factorial points (coded levels as $(+1)$ and $(-1))$, four star points (coded as $(+\sqrt{ } 2)$, and $(-\sqrt{ } 2))$ and three centre points (coded as 0 ) (Table 1 ).

2.7. Statistical Analysis. With CCRD, 5 levels for each factor were used which enabled to fit second-order polynomials to the experimental data points. The results of each CCRD were analyzed using the software "Statistic," version 6, from StatSoft, USA. Both linear and quadratic effects of the two variables under study, as well as their interactions, on $\beta$-Dglucosidase and $\alpha$-L-rhamnosidase activities were calculated. Their significance was evaluated by analysis of variance.

Experimental data were fitted to a second-order polynomial model and the regression coefficients obtained. The generalized second-order polynomial model used in the response surface analysis was as follows:

$$
Y=\beta_{0}+\beta_{1} X_{1}+\beta_{2} X_{2}+\beta_{11} X_{1}^{2}+\beta_{22} X_{2}^{2}+\beta_{12} X_{1} X_{2},
$$

where $\beta_{0}, \beta_{1}, \beta_{2}, \beta_{11}, \beta_{22}$, and $\beta_{12}$ are the regression coefficients for intercept, linear, quadratic and interaction terms, respectively, and $X_{1}$ and $X_{2}$ are the independent variables, temperature and $\mathrm{pH}$.

The fit of the models was evaluated by the determination coefficients $\left(R^{2}\right)$ and adjusted $R^{2}\left(R_{\text {adj }}^{2}\right)$.

2.8. Verification Experiments. Optimal conditions for the inactivation of $\beta$-D-glucosidase activity of naringinase keeping $\alpha$-L-rhamnosidase with a high activity were dependent on temperature and $\mathrm{pH}$ conditions obtained using the predictive model equations of RSM. The experimental and predicted values were compared in order to determine the validity of the model.

\subsection{Methods for Flavonoid Production and Purification.} Prunin was obtained through the hydrolysis of a $10 \mathrm{mM}$ naringin solution, using $50 \mathrm{mg} \mathrm{L}^{-1}$ of naringinase, with its $\beta$ $\mathrm{D}$-glucosidase selectively inactivated, in $20 \mathrm{mM}$ citrate buffer, $\mathrm{pH} 3.4,60.0^{\circ} \mathrm{C}$ for 6 hours. Prunin precipitated after 12 hours at $4^{\circ} \mathrm{C}$ and was recovered through vacuum filtration. Consecutively it was dissolved in hot water and was filtered. Prunin was obtained through recrystallization from water.

Naringenin was obtained through the hydrolysis of a $10 \mathrm{mM}$ naringin solution, using $50 \mathrm{mg} \mathrm{L}^{-1}$ of naringinase in $20 \mathrm{mM}$ acetate buffer, $\mathrm{pH} 4.0,60.0^{\circ} \mathrm{C}$ for 6 hours. Naringenin precipitated after 12 hours at $4^{\circ} \mathrm{C}$ and was recovered through vacuum filtration. Consecutively it was dissolved in hot ethanol and filtered. Naringenin was obtained through recrystallization from ethanol and water.

Isoquercetin was obtained through the hydrolysis of a $5 \mathrm{mM}$ rutin solution, using $50 \mathrm{mg} \mathrm{L}^{-1}$ of naringinase, with $\beta$-D-glucosidase activity selectively inactivated, in $20 \mathrm{mM}$ citrate buffer, $\mathrm{pH} 3.4,60.0^{\circ} \mathrm{C}$ for 6 hours. Isoquercetin precipitated after 12 hours at $4^{\circ} \mathrm{C}$ and was recovered through vacuum filtration. Consecutively it was dissolved in hot ethanol and was filtered. Isoquercetin was obtained through recrystallization from ethanol and water.

Quercetin was obtained through the hydrolysis of a $5 \mathrm{mM}$ rutin solution, using $50 \mathrm{mg} \mathrm{L}^{-1}$ of naringinase in 
TABLE 2: Optimum $\mathrm{pH}$ values for the hydrolysis of 4-NGP and 4 -NRP with $\beta$-D-glucosidase and $\alpha$-L-rhamnosidase activities of naringinase.

\begin{tabular}{lccc}
\hline Substrate & $\begin{array}{c}\text { Optimum } \\
\mathrm{pH}\end{array}$ & $\begin{array}{c}\text { Nonlinear } \\
\text { parameters }\end{array}$ & $r^{2}$ \\
\hline & & $A_{\max }=0.060$, & \\
4-NGP & 4.1 & $\mathrm{p} K_{1}=2.6$, & 0.892 \\
& & $\mathrm{p} K_{2}=5.5$ & \\
& & $A_{\max }=0.181$, & \\
4 -NRP & 3.4 & $\mathrm{p} K_{1}=1.3$, & 0.984 \\
& & $\mathrm{p} K_{2}=5.6$ & \\
\hline
\end{tabular}

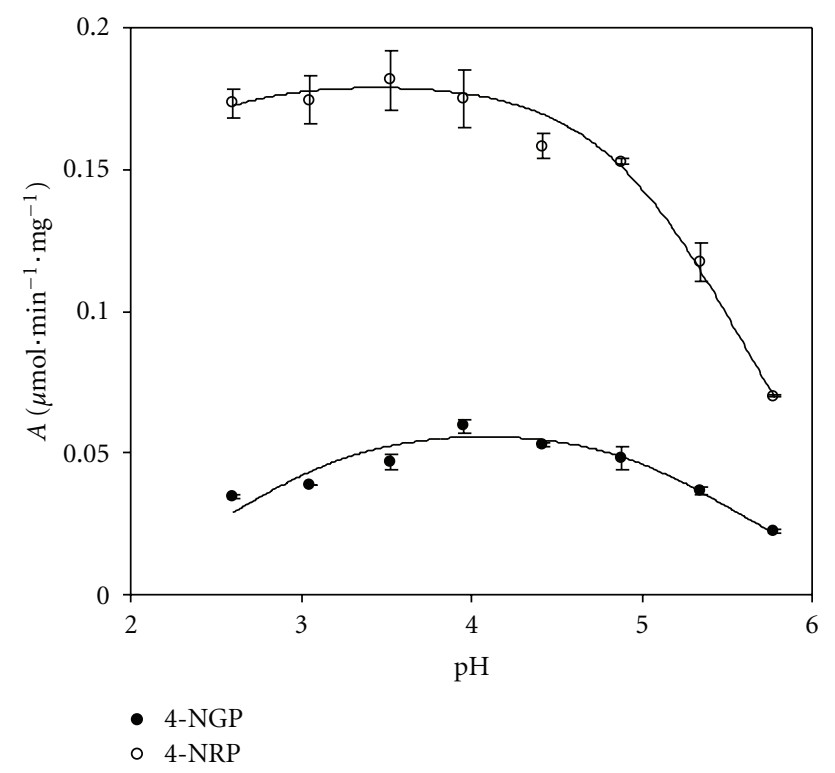

Figure 2: $\mathrm{pH}$ profile of 4-NGP and 4-NRP hydrolysis using naringinase in sodium citrate buffer $20 \mathrm{mM}$ (mean value \pm standard error).

$20 \mathrm{mM}$ acetate buffer, $\mathrm{pH} 4.0,60.0^{\circ} \mathrm{C}$ for 6 hours. Quercetin precipitated after 12 hours at $4^{\circ} \mathrm{C}$ and was recovered through vacuum filtration. Consecutively it was dissolved in hot ethanol and was filtered. Quercetin was obtained through recrystallization from ethanol and water.

\section{Results and Discussion}

3.1. $p H$ Profile. The activity $\mathrm{pH}$ profile of both $\alpha$-Lrhamnosidase and $\beta$-D-glucosidase activities of naringinase was studied hydrolysing the specific substrates, 4-NRP and 4-NGP, respectively. This $\mathrm{pH}$ profile was studied between 2.5 and 5.8, in citrate buffer. Figure 2 shows the distinct activity $\mathrm{pH}$ profiles of $\alpha$-L-rhamnosidase and $\beta$-D-glucosidase activities of naringinase. From these studies and adjusting the model of (1), the optimum $\mathrm{pH}$ was found to be 3.4 and 4.1 , respectively, with a maximum specific activity of 0.181 and $0.060 \mu \mathrm{mol} \mathrm{mg}^{-1} \mathrm{~min}^{-1}$, for $\alpha$-L-rhamnosidase and $\beta$ $\mathrm{D}$-glucosidase activities of naringinase (Table 2 ). Jurado et al. [19] adjusted a similar model to the experimental data of $\beta$ D-galactosidase activity versus $\mathrm{pH}$.
In a previous work [20] the specific activity of $\beta$-D-glucosidase in $20 \mathrm{mM}$ acetate buffer, $\mathrm{pH} 4.0$ was $0.086 \mu \mathrm{mol} \mathrm{min} \mathrm{mg}^{-1} \mathrm{mg}^{-1}$, while in this study, in $20 \mathrm{mM}$ citrate buffer, $\mathrm{pH} 4.0$ it was found to be $0.060 \mu \mathrm{mol} \mathrm{min} \mathrm{mg}^{-1} \mathrm{mg}^{-1}$. This lower $\beta$-D-glucosidase specific activity corresponded to a $30 \%$ activity decrease when citrate buffer was used instead of acetate. These results highlight the importance of buffer (citrate) and $\mathrm{pH}(3.4)$ to selectively inactivate $\beta$ D-glucosidase activity of naringinase. Norouzian et al. [22] observed a naringinase activity inhibition with $20 \mathrm{mM}$ citric acid buffer. In further studies of $\beta$-D-glucosidase inactivation citrate buffer was used as bioreaction media.

3.2. Inactivation Kinetics. Naringinase was inactivated using combined temperature and $\mathrm{pH}$ conditions, between 75.0$85.0^{\circ} \mathrm{C}$ and 3.2-6.0, respectively. Thus, temperature and $\mathrm{pH}$ on stability of $\beta$-D-glucosidase and $\alpha$-L-rhamnosidase were evaluated on a minimum set of optimal selected experiments. The inactivation behaviour for $\beta$-D-glucosidase and $\alpha$-Lrhamnosidase activities of naringinase was distinct from each other under the same temperature and $\mathrm{pH}$ conditions (Figure 3).

To describe the inactivation kinetics for $\beta$-D-glucosidase and $\alpha$-L-rhamnosidase activities of naringinase, residual activity $\left(A_{r}\right)$ was defined as the ratio between the specific activity after each time inactivation period (A) and the specific activity without inactivation $\left(A_{0}\right)$.

Both $\mathrm{pH}$ and temperature treatments could be described adequately by a series-type enzyme inactivation model (3) involving first-order steps in an inactivation sequence as well as an active intermediate:

$$
A_{0} \stackrel{k_{1}}{\rightarrow} A_{1} \stackrel{k_{2}}{\longrightarrow} A_{2}
$$

A biphasic inactivation nature was observed for $\beta$-Dglucosidase with a final state totally inactivated $\left(\alpha_{2}=0\right)$ adjusted to (4) [23].

$$
A_{r}=\left[1+\frac{\alpha_{1} k_{1}}{k_{2}-k_{1}}\right] e^{-k_{1} t}-\left[\frac{\alpha_{1} k_{1}}{k_{2}-k_{1}}\right] e^{-k_{2} t}
$$

$k_{1}$ and $k_{2}$ were the first and second deactivation rate coefficients, respectively; $A_{0}, A_{1}$, and $A_{2}$ were the specific activities of the initial active enzyme, enzyme intermediate, and final enzyme state, respectively; $\alpha_{1}$ was the specific activities ratio $A_{1} A_{0}^{-1}$ and $A_{2} A_{0}^{-1}$, respectively. A first inactivation step was followed by a second one with the existence of an enzymatic intermediate having a lower specific activity than the initial enzyme native state $\left(\alpha_{1}<1\right)$ (Table 3$)$ and a final state where the enzyme is completely inactivated $\left(\alpha_{2}=0\right)$ [23]. The first faster deactivation step observed may correspond to the unfolding of the carbohydrate portion, lowering its activity relative to the initial state $\left(\alpha_{1}\right)$; afterwards, the second slower step may apply to the embodiment of enzyme inactivation.

On the other hand, $\alpha$-L-rhamnosidase inactivation as well as the inactivation of $\beta$-D-glucosidase under the conditions of $80.0^{\circ} \mathrm{C}$ and $\mathrm{pH} 4.6$, occurred according to the 


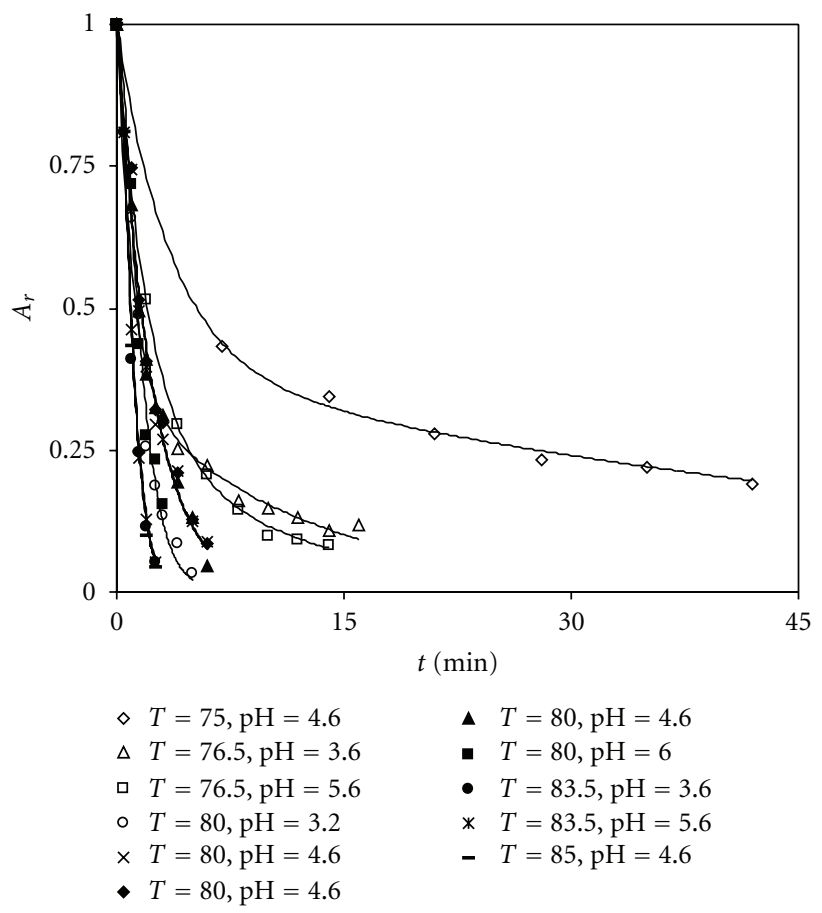

(a)

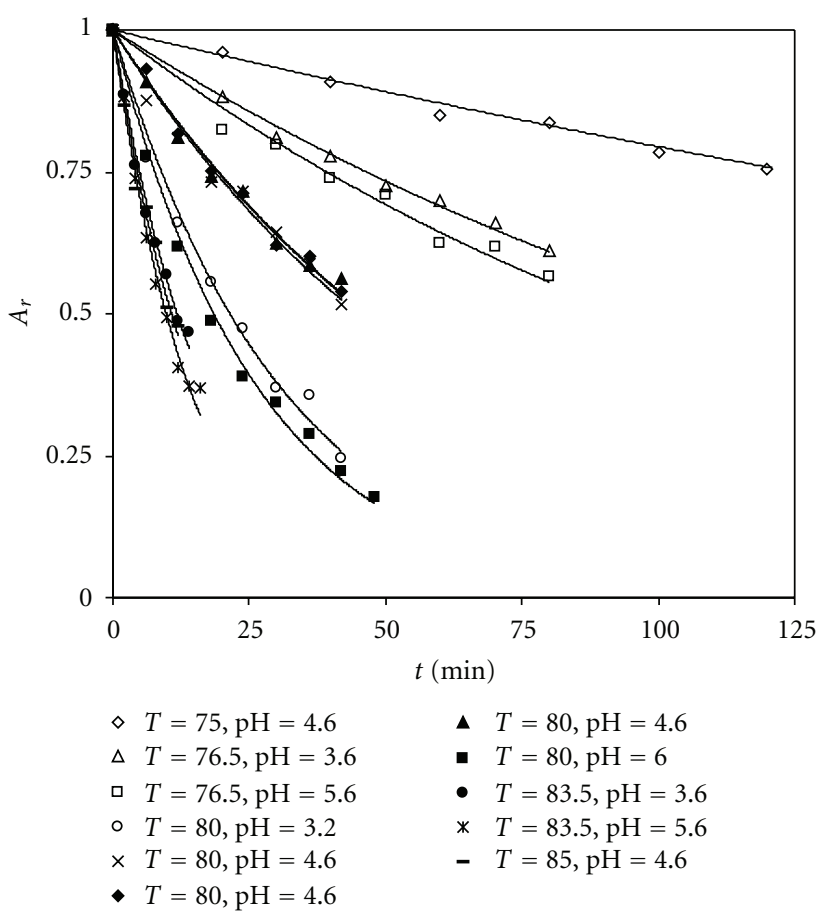

(b)

Figure 3: Thermal inactivation under combined temperature and $\mathrm{pH}$ conditions of $\beta$-D-glucosidase (a) and $\alpha$-L-rhamnosidase (b) activities of naringinase.

classical first-order inactivation model (Figure 3)

$$
A_{r}=e^{-k_{1} t}
$$

Table 3 shows the inactivation parameters determined at different temperature and $\mathrm{pH}$ conditions for both $\beta$-Dglucosidase and $\alpha$-L-rhamnosidase.

Tsen et al. [24] and Ellenrieder and Daz [25] reported naringinase (from Penicillium decumbens) deactivation profiles at $\mathrm{pH}$ 3.5-3.7. $\alpha$-L-Rhamnosidase from Aspergillus terreus [26] and Aspergillus nidulans [27] when incubated at $\mathrm{pH}$ values lower than 4.0 rapidly lost activity, whereas Aspergillus aculeatus [28] was shown to be insensitive to $\mathrm{pH}$ in the range 3-8. Comparing our results with available stability data of purified fungal $\alpha$-L-rhamnosidases referred by different authors $[26,27,29,30]$, it can be pointed out that our developed method avoiding $\alpha$-L-rhamnosidase purification with $\beta$-D-glucosidase inactivation is an effective and cheap method.

3.3. RSM. In this study a central composite design and response surface methodology (RSM) were applied in order to acquire $\mathrm{pH}$-temperature conditions to selectively inactivate $\beta$-D-glucosidase activity expression from naringinase, keeping $\alpha$-L-rhamnosidase with high activity. The experiments were carried out according to a design $2^{2}$ and a CCRD, as a function of both the temperature $(T)$ and $\mathrm{pH}$. The obtained results, $\alpha$-L-rhamnosidase residual activity of naringinase corresponding to a $\beta$-D-glucosidase inactivation, were used to calculate the significant effects, either linear or quadratic, of the 4-NRP hydrolysis reaction.

The experimental results showed that $\alpha$-L-rhamnosidase residual activity and $\beta$-D-glucosidase inactivation were affected by $\mathrm{pH}$ and temperature individually and interactively (Figure 4 ). In Table 4 are presented the effects and respective significant levels $(P)$ of the temperature $(T)$, $\mathrm{pH}$, and interaction $(T \times \mathrm{pH})$ on the $\alpha$-L-rhamnosidase residual activity. Therefore, negative effects of the factors temperature $(T)$ or $\mathrm{pH}$ or their interaction $(T \times \mathrm{pH})$ indicate that the response decreased with the increase in these factors. Linear and quadratic terms of temperature were highly significant, $P<0.001$, while the linear and quadratic terms of $\mathrm{pH}$ were significant $(P<0.05)$ for $\alpha$ L-rhamnosidase activity (Table 4$)$. A negative interaction between the variables tested $(T \times \mathrm{pH})$ on $\alpha$-L-rhamnosidase activity indicated that higher activities are obtained at higher temperatures and lower $\mathrm{pH}$ within the experimental domain.

In addition, RSM was also applied to the first deactivation rate coefficients $\left(k_{1}\right)$ for $\alpha$-L-rhamnosidase and $\beta$-Dglucosidase obtained at the different experimental conditions tested (Table 3). It was not possible to apply RSM to the parameters $\alpha_{1}$ and $k_{2}$, as shown in Table 3, because the models are adjusted at different conditions.

Moreover, in Figure 4 is presented the effects of temperature and $\mathrm{pH}$ on the first deactivation rate coefficient $\left(k_{1}\right)$ for $\alpha$-L-rhamnosidase and $\beta$-D-glucosidase activities 


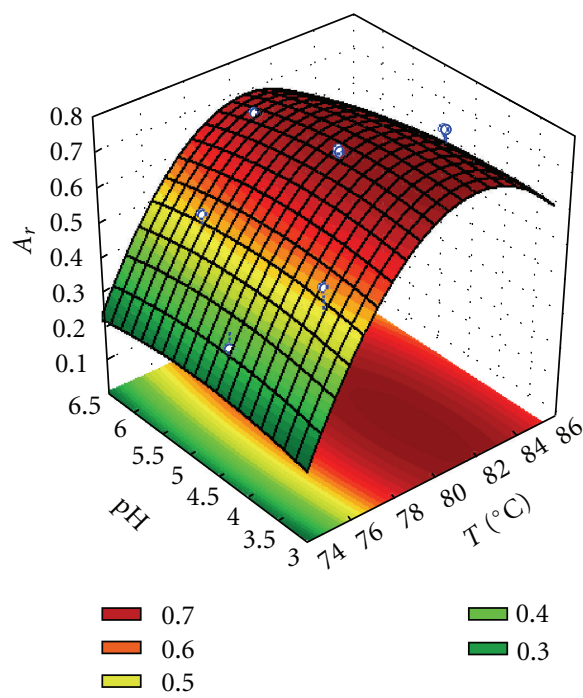

$Z=-63.67172886+1.56545105 x-0.00952257 x^{z}+$

$0.36612952 Y-0.01229616 Y^{z}-0.00331921 X Y$

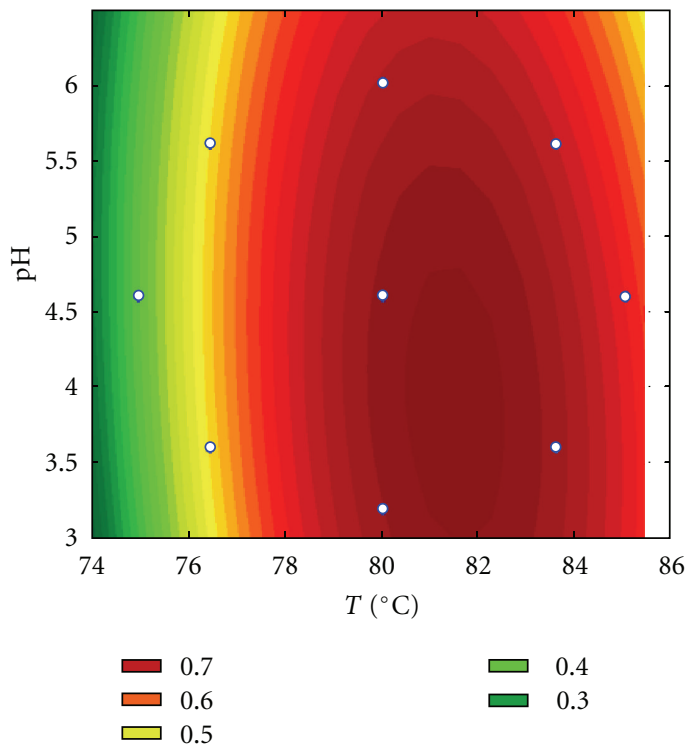

(b.1)
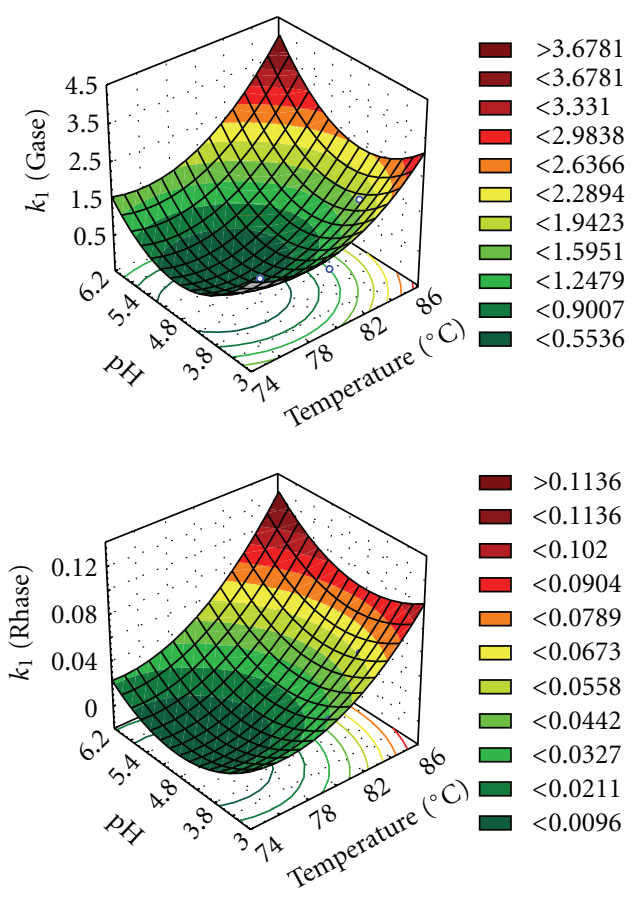
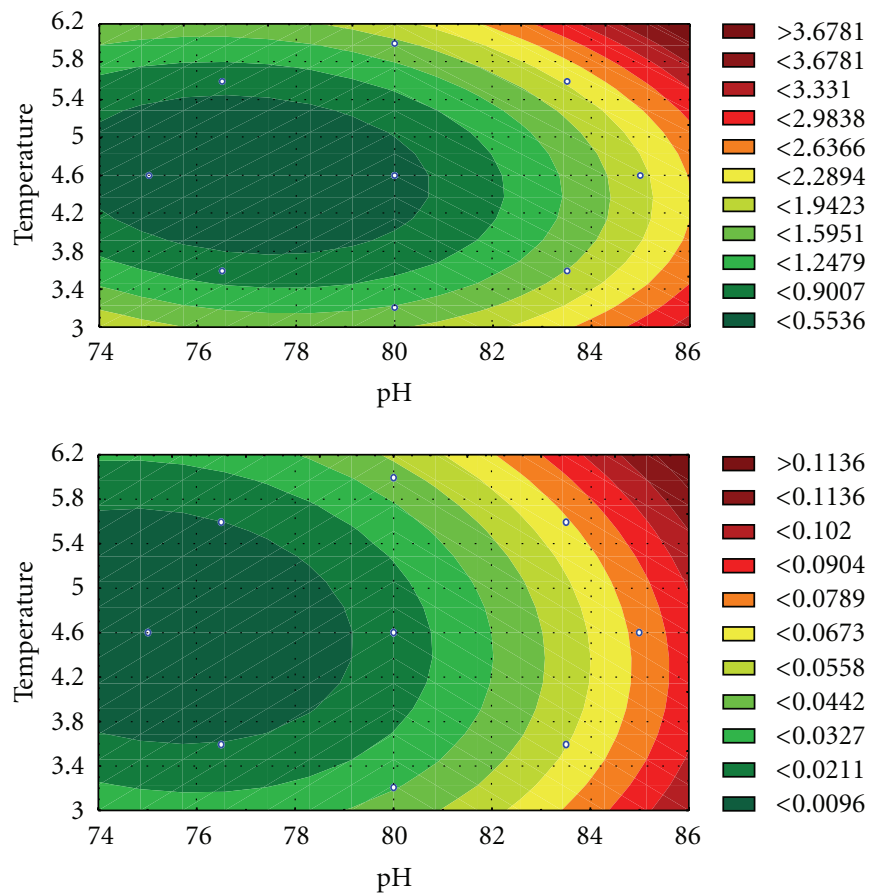

(b.2)

Figure 4: Response surfaces fitted to the experimental data points corresponding to (a) $\alpha$-L-rhamnosidase residual activity and (b) to first deactivation rate coefficients $\left(k_{1}\right)$ for (b.1) $\alpha$-L-rhamnosidase (rhase) and (b.2) $\beta$-D-glucosidase (gase) activities of naringinase, as a function of temperature $(T)$ and $\mathrm{pH}$.

of naringinase. Highly significant effects $(P<0.001)$ were obtained for $k_{1}$ of $\beta$-D-glucosidase inactivation at different $\mathrm{pH}$ and temperature conditions (Table 4 ). The first deactivation rate coefficient $\left(k_{1}\right)$ of $\alpha$-L-rhamnosidase and $\beta$-D-glucosidase increased with temperature and $\mathrm{pH}$ (Figure 4).
A least-squares technique was used to fit quadratic polynomial models and obtain multiple regression coefficients for $\alpha$-L-rhamnosidase activity which are summarized in Table 5. Examination of these coefficients indicated that temperature effects on $\alpha$-L-rhamnosidase activity both linear and quadratic terms were highly significant, 
TABLE 3: Thermal inactivation parameters of $\beta$-D-glucosidase and $\alpha$-L-rhamnosidase activities of naringinase, under combined temperature and $\mathrm{pH}$ conditions.

\begin{tabular}{|c|c|c|c|c|c|c|c|c|}
\hline \multirow{2}{*}{$T\left({ }^{\circ} \mathrm{C}\right)$} & \multirow{2}{*}{$\mathrm{pH}$} & \multicolumn{4}{|c|}{$\beta$-D-glucosidase } & \multicolumn{2}{|c|}{$\alpha$-L-rhamnosidase } & \multirow{2}{*}{$A_{r}(\alpha$-L-rhamnosidase $)$} \\
\hline & & $\alpha_{1}$ & $k_{1}\left(h^{-1}\right)$ & $k_{2}$ & $r^{2}$ & $k_{1}\left(h^{-1}\right)$ & $r^{2}$ & \\
\hline 75.0 & 4.6 & 0.376 & 0.283 & 0.017 & 0.999 & 0.0023 & 0.990 & 0.33 \\
\hline 76.5 & 3.6 & 0.327 & 0.990 & 0.084 & 0.997 & 0.0062 & 0.994 & 0.57 \\
\hline 76.5 & 5.6 & 0.226 & 0.486 & 0.093 & 0.999 & 0.0073 & 0.980 & 0.56 \\
\hline 80.0 & 3.2 & - & 0.579 & - & 0.971 & 0.0323 & 0.989 & 0.73 \\
\hline 80.0 & 4.6 & - & 0.428 & - & 0.980 & 0.0154 & 0.979 & 0.74 \\
\hline 80.0 & 4.6 & - & 0.434 & - & 0.990 & 0.0149 & 0.991 & 0.75 \\
\hline 80.0 & 4.6 & - & 0.431 & - & 0.992 & 0.0149 & 0.996 & 0.75 \\
\hline 80.0 & 6.0 & - & 0.547 & - & 0.953 & 0.0375 & 0.995 & 0.71 \\
\hline 83.5 & 3.6 & - & 0.869 & - & 0.987 & 0.0589 & 0.989 & 0.71 \\
\hline 83.5 & 5.6 & - & 0.838 & - & 0.953 & 0.0711 & 0.991 & 0.65 \\
\hline 85.0 & 4.6 & - & 0.868 & - & 0.997 & 0.0646 & 0.979 & 0.68 \\
\hline
\end{tabular}

TABLE 4: Effects and respective significance levels $(P)$ of temperature $(T)$ and $\mathrm{pH}$ on $\alpha$-L-rhamnosidase residual activity $\left(A_{r}\right)$ and on first deactivation rate coefficient $\left(k_{1}\right)$ for $\alpha$-L-rhamnosidase and $\beta$-Dglucosidase activities of naringinase.

\begin{tabular}{|c|c|c|c|}
\hline Variable & $\begin{array}{c}A_{r} \\
(\alpha-\mathrm{L}- \\
\text { rhamnosidase })\end{array}$ & $\begin{array}{c}k_{1} \\
(\alpha-\mathrm{L}- \\
\text { rhamnosidase })\end{array}$ & $\begin{array}{c}k_{1} \\
(\beta-\mathrm{D}- \\
\text { glucosidase })\end{array}$ \\
\hline$T$ (linear term) & $18.1467^{* * *}$ & $0.0509 * * *$ & $1.0856^{* * *}$ \\
\hline$T$ (quadratic term) & $-23.8667^{* * *}$ & $0.0188^{* *}$ & $0.6455^{* * *}$ \\
\hline $\mathrm{pH}$ (linear term) & $-2.5064^{*}$ & 0.0052 & $0.1745^{* * *}$ \\
\hline $\mathrm{pH}$ (quadratic term) & $-2.4592^{*}$ & $0.0211^{* *}$ & $0.9921 * * *$ \\
\hline$T \times \mathrm{pH}$ & -2.3500 & 0.0055 & $0.223^{* * *}$ \\
\hline
\end{tabular}

$* P<0.05 ;{ }^{* *} P<0.01 ;{ }^{* * *} P<0.001$.

$P<0.001$ (Table 5). The linear and quadratic terms of $\mathrm{pH}$ were significant on $\alpha$-L-rhamnosidase activity $(P<0.05)$ (Table 5). Moreover, linear and quadratic terms had high and significant effects $(P<0.001$ and $P<0.05)$ on first deactivation rate coefficient of $\alpha$-L-rhamnosidase, while for $\beta$-D-glucosidase significant effects are presented $(P<0.01$ and $P<0.05$ ) (Table 5).

Therefore, curved surfaces were fitted to the experimental data (Figure 4). Partial differentiation of these polynomial equations was used to find the optimum points, that is, the stationary points. The least-square estimates of the coefficients of the model were calculated from the values of the response for each experiment in the chosen experimental matrix. The relationships between independent and dependent variables in the three-dimensional representations are convex surfaces, for $\alpha$-L-rhamnosidase activity (Figure 4 ). The obtained response surface (Figure 4) was described by second-order polynomial equations to the experimental data points, as a function of temperature and $\mathrm{pH}$ (Table 5). In the design of these models, the significant effects $(P<0.05)$ and those that presented a confident range smaller than the value of the effect or smaller than the standard deviation were included in these model equations. In fact, these later effects have a lower probability, but their values are not small enough to be neglected.

The high values of $R^{2}$ and $R_{\text {adj }}^{2}$ of the model (Table 5) showed a close agreement between the experimental results and the theoretical values predicted by the model [10]. The adjusted coefficients of determination for $\alpha$-L-rhamnosidase activity $\left(R_{\text {adj }}^{2}=0.936\right)$ implied that $93.6 \%$ of the variations could be explained by the fitted model.

The ANOVA for the two response variables (temperature and $\mathrm{pH}$ ) indicated that the model developed for $\alpha$-Lrhamnosidase activity was adequate with the linear and the quadratic term with high significant effect $(<0.05 \%)$ (data not showed).

The regression models allowed the prediction of the effects of the two parameters, temperature and $\mathrm{pH}$ on $\alpha$ L-rhamnosidase activity and $\beta$-D-glucosidase inactivation. These optimal conditions were a temperature of $81.5^{\circ} \mathrm{C}$ and pH 3.9 (Table 6).

Once tested, the model may be used to predict the value of the response(s) under any conditions within the experimental region.

These results showed how naringinase can be used to selectively catalyze reactions like glycosides hydrolysis towards monoglycosylated flavonoids.

3.4. Verification of the Optimal Temperature and $p H$ Inactivation Conditions. The optimal conditions of temperature and $\mathrm{pH}$ found using RSM (Table 6) were tested experimentally in order to confirm the predicted results.

Figure 5 shows the inactivation profiles of both $\beta$-Dglucosidase and $\alpha$-L-rhamnosidase under $81.5^{\circ} \mathrm{C}$ and $\mathrm{pH}$ 3.9. Moreover, the verification experiments proved that the predicted values for $\alpha$-L-rhamnosidase residual activity (0.77) for the model was satisfactorily achieved within more than $95 \%$ confidence interval. The time needed for $\beta$-Dglucosidase activity to reach $0.01 \%$ of $\alpha$-L-rhamnosidase activity was determined through extrapolation of $\beta$-Dglucosidase inactivation and corresponded to 15 minutes and 26 seconds. At this time the $\alpha$-L-rhamnosidase residual 
TABLE 5: Second-order model equations for the response surfaces fitted to the experimental data points of $\alpha$-L-rhamnosidase residual activity $\left(A_{r}\right)$, on first deactivation rate coefficient $\left(k_{1}\right)$ for $\alpha$-L-rhamnosidase and $\beta$-D-glucosidase activities of naringinase, as a function of temperature $(T)$ and $\mathrm{pH}$, and respective $R^{2}$ and $R_{\mathrm{adj}}^{2}$.

\begin{tabular}{lccccc}
\hline Coefficient & $\begin{array}{c}A_{r} \\
(\alpha \text {-L-rhamnosidase })\end{array}$ & $P$ & $\begin{array}{c}k_{1} \\
(\alpha \text {-L-rhamnosidase })\end{array}$ & $\begin{array}{c}k_{1} \\
(\beta \text {-D-glucosidase })\end{array}$ \\
\hline$\beta_{0}$ & -63.6717 & 0.0004 & 4.8541 & 0.0068 & 178.4516 \\
Linear & & & & & 0.0419 \\
$\beta_{1}$ & 1.5645 & 0.0004 & -0.1193 & 0.0064 & -4.2067 \\
$\beta_{2}$ & 0.3661 & 0.0322 & -0.1579 & 0.0436 & -7.0252 \\
Quadratic & & & & 0.0456 \\
$\beta_{11}$ & -0.0095 & 0.0004 & 0.00077 & 0.0055 & 0.0263 \\
$\beta_{22}$ & -0.0123 & 0.0355 & 0.01056 & 0.0039 & 0.4961 \\
Cross-product & & & & 0.0443 \\
$\beta_{12}$ & 0.0033 & 0.0530 & 0.00079 & 0.3056 & 0.0106 \\
$R^{2}$ & 0.936 & - & 0.9812 & - & 0.03186 \\
$R_{\text {adj }}^{2}$ & 0.872 & - & 0.9624 & - & 0.9047 \\
\hline
\end{tabular}

TABle 6: Verification of the developed model for $\beta$-D-glucosidase inactivation at optimal temperature and $\mathrm{pH}$ conditions leading the best $\alpha$-L-rhamnosidase residual activity of naringinase.

\begin{tabular}{lcc}
\hline & Predicted & Experimental \\
\hline Temperature $\left({ }^{\circ} \mathrm{C}\right)$ & 81.5 & 81.5 \\
$\mathrm{pH}$ & 3.9 & 3.9 \\
Time $(\min )$ & 16 & 16 \\
$\begin{array}{l}\alpha \text {-L-rhamnosidase } \\
\text { residual activity }\end{array}$ & 0.77 & 0.78 \\
$\begin{array}{l}\beta \text {-D-glucosidase } \\
\text { residual activity }\end{array}$ & 0.0001 & 0.0001 \\
\hline
\end{tabular}

activity was 0.78 which is quite similar to the value predicted with RSM (Table 6).

3.5. Production and Identification of Bioactive Compounds. Once $\beta$-D-glucosidase of naringinase was selectively inactivated, the residual $\alpha$-L-rhamnosidase activity was used for the production of flavonoids glycosides starting from rutinosides, (c.f. Section 2.9) (Figure 6). Adequate purification procedures were used, and compounds identification was carried out through HPLC LC-MS analysis.

Naringin enzymatic hydrolysis lead to prunin, a very expensive product. Isoquercetin was obtained from rutin enzymatic hydrolysis in a production yield of $61 \%$.

The aglycones were also produced from rutinosides using native naringinase, expressing $\alpha$-L-rhamnosidase and $\beta$-Dglucosidase. As long as a sugar moiety was removed from the rutinoside to the aglycone, a polarity decrease was observed, as shown in Figure 6. Naringenin was obtained with a production yield of $49 \%$ from naringin, while quercetin was obtained from rutin (Figure 2 ) in a yield of $86 \%$.

These outcomes showed the high potential of the developed method on the production of monoglycosylated flavonoids.

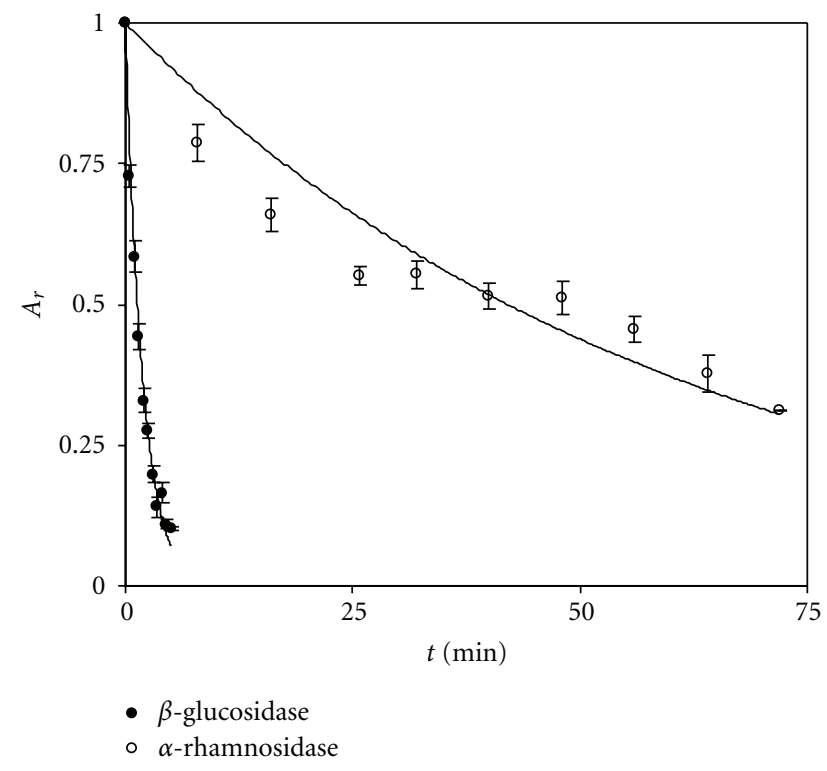

FIGURE 5: Inactivation kinetics of $\beta$-D-glucosidase and $\alpha$-Lrhamnosidase activities of naringinase at $81.5^{\circ} \mathrm{C}$ and $\mathrm{pH}$ 3.9.

\section{Conclusions}

The inactivation of $\beta$-D-glucosidase activity of naringinase was affected by $\mathrm{pH}$ and temperature individually and interactively, in citrate buffer. This inactivation could be described by response surfaces that enabled to fit secondorder polynomials equations. A closed agreement between the experimental $\alpha$-L-rhamnosidase residual activity (0.78) and the predicted value by the model $(0.77)$ made RSM an appropriate tool to achieve temperature and $\mathrm{pH}$ optimized values for the selective inactivation of $\beta$-D-glucosidase activity of naringinase, at $81.5^{\circ} \mathrm{C}, \mathrm{pH} 3.9$ for 16 minutes.

These are high innovative and sounding results showing the potential of the efficient and cheap developed method 


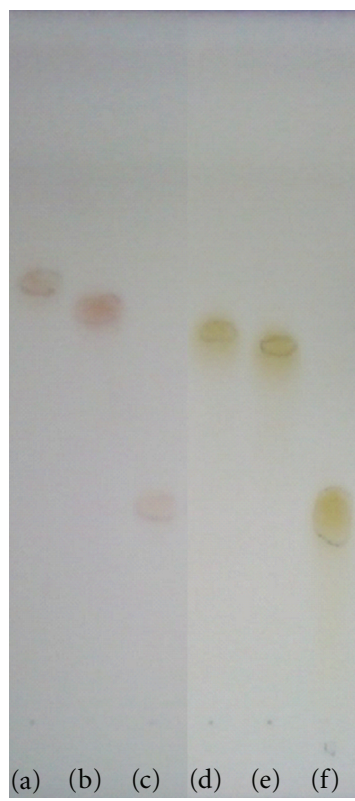

\begin{tabular}{lcccc}
\hline \multicolumn{1}{c}{ Compound } & Rf & $\begin{array}{c}\text { Visible } \\
\text { light }\end{array}$ & $\begin{array}{c}\text { UV light } \\
(254 \mathrm{~nm})\end{array}$ & $\begin{array}{c}\text { Acid revelation } \\
+ \text { heating }\left(150^{\circ} \mathrm{C}\right)\end{array}$ \\
\hline (a) Naringin & 0.62 & Invisible & Visible & Orange \\
(b) Prunin & 0.58 & Invisible & Visible & Orange \\
(c) Naringenin & 0.3 & Invisible & Visible & Orange \\
(d) Rutin & 0.55 & Yellow & Visible & Yellow \\
(e) Isoquercetin & 0.53 & Yellow & Visible & Yellow \\
(f) Quercetin & 0.3 & Yellow & visible & Yellow \\
\hline
\end{tabular}

Figure 6: TLC of $(\mathrm{a})$ naringin $(\mathrm{Rf}=0.62),(\mathrm{b})$ prunin $(\mathrm{Rf}=0.58),(\mathrm{c})$ naringenin $(\mathrm{Rf}=0.30),(\mathrm{d})$ rutin $(\mathrm{Rf}=0.55),(\mathrm{e})$ isoquercetin $(\mathrm{Rf}=$ $0.53)$, and $(\mathrm{f})$ quercetin $(\mathrm{Rf}=0.30)$. All of compounds were visible with $\mathrm{UV}$ light $(254 \mathrm{~nm})$. After acid revelation + heating $\left(150^{\circ} \mathrm{C}\right)$, naringin, prunin, and naringenin showed orange spots and rutin, quercetin, and isoquercetin, yellow.

for the production of flavonoid glycosides starting from rutinosides.

\section{Acknowledgments}

H. V. Real was supported by Fundação para a Ciência e a Tecnologia, Portugal, Grant no. SFRH/BD/30716/2006. The authors would like to acknowledge FCT for funding the project: 650 REDE/1518/REM/2005 that allowed the LC-MS analysis.

\section{References}

[1] P. C. H. Hollman, M. N. C. P. Bijsman, Y. Van Gameren, E. P. J. Cnossen, J. H. M. De Vries, and M. B. Katan, "The sugar moiety is a major determinant of the absorption of dietary flavonoid glycosides in man," Free Radical Research, vol. 31, no. 6, pp. 569-573, 1999.

[2] C. Martinez, O. Vicente, G. Yanez et al., "Treatment of metastatic melanoma B16F10 by the flavonoids tangeretin, rutin, and diosmin," Journal of Agricultural and Food Chemistry, vol. 53, no. 17, pp. 6791-6797, 2005.

[3] Y. Kawai, T. Nishikawa, Y. Shiba et al., "Macrophage as a target of quercetin glucuronides in human atherosclerotic arteries: implication in the anti-atherosclerotic mechanism of dietary flavonoids," Journal of Biological Chemistry, vol. 283, no. 14, pp. 9424-9434, 2008.

[4] E. Bellocco, D. Barreca, G. Laganà et al., "Influence of L-rhamnosyl-D-glucosyl derivatives on properties and biological interaction of flavonoids," Molecular and Cellular Biochemistry, vol. 321, no. 1-2, pp. 165-171, 2009.

[5] L. Zhang, W. Liu, T. Hu et al., "Structural basis for catalytic and inhibitory mechanisms of $\beta$-hydroxyacyl-acyl carrier protein dehydratase (FabZ)," Journal of Biological Chemistry, vol. 283, no. 9, pp. 5370-5379, 2008.

[6] C. I. G. Tuberoso, P. Montoro, S. Piacente et al., "Flavonoid characterization and antioxidant activity of hydroalcoholic extracts from Achillea ligustica All," Journal of Pharmaceutical and Biomedical Analysis, vol. 50, no. 3, pp. 440-448, 2009.

[7] H. J. Vila Real, A. J. Alfaia, A. R. T. Calado, and M. H. L. Ribeiro, "High pressure-temperature effects on enzymatic activity: naringin bioconversion," Food Chemistry, vol. 102, no. 3, pp. 565-570, 2007.

[8] I. A. C. Ribeiro and M. H. L. Ribeiro, "Kinetic modelling of naringin hydrolysis using a bitter sweet alfarhamnopyranosidase immobilized in k-carrageenan," Journal of Molecular Catalysis B, vol. 51, no. 1-2, pp. 10-18, 2008.

[9] I. A. Ribeiro and M. H. L. Ribeiro, "Naringin and naringenin determination and control in grapefruit juice by a validated HPLC method," Food Control, vol. 19, no. 4, pp. 432-438, 2008.

[10] L. Vuataz, Statistical Procedures in Food Research, Elsevier, London, UK, 1986, Edited by J. R. Piggott.

[11] J. Marques, H. J. Vila-Real, A. J. Alfaia, and M. H. L. Ribeiro, "Modelling of the high pressure-temperature effects on naringin hydrolysis based on response surface methodology," Food Chemistry, vol. 105, no. 2, pp. 504-510, 2007.

[12] M. H. L. Ribeiro, D. Silveira, C. Ebert, and S. Ferreira-Dias, "Response surface modelling of the consumption of bitter compounds from orange juice by Acinetobacter calcoaceticus," Journal of Molecular Catalysis B, vol. 21, no. 1-2, pp. 8188, 2003.

[13] M. Inês Amaro, J. Rocha, H. Vila-Real et al., "Antiinflammatory activity of naringin and the biosynthesised naringenin by naringinase immobilized in microstructured materials in a model of DSS-induced colitis in mice," Food Research International, vol. 42, no. 8, pp. 1010-1017, 2009. 
[14] J. A. Vázquez, M. P. González, and M. A. Murado, "Preliminary tests on nisin and pediocin production using waste protein sources: factorial and kinetic studies," Bioresource Technology, vol. 97, no. 4, pp. 605-613, 2006.

[15] M. H. Ribeiro, S. Manha, and L. Brito, "The effects of salt and $\mathrm{pH}$ stress on the growth rates of persistent strains of Listeria monocytogenes collected from specific ecological niches," Food Research International, vol. 39, no. 7, pp. 816-822, 2006.

[16] D. Mamma, E. Kalogeris, D. G. Hatzinikolaou et al., "Biochemical characterization of the multi-enzyme system produced by Penicillium decumbens grown on rutin," Food Biotechnology, vol. 18, no. 1, pp. 1-18, 2004.

[17] S. Gocan and G. Cimpan, "Review of the analysis of medicinal plants by TLC: modern approaches," Journal of Liquid Chromatography and Related Technologies, vol. 27, no. 7-9, pp. 1377-1411, 2004.

[18] G. Pekin, F. Vardar-Sukan, and N. Kosaric, "Production of sophorolipids from Candida bombicola ATCC 22214 using Turkish corn oil and honey," Engineering in Life Sciences, vol. 5, no. 4, pp. 357-362, 2005.

[19] E. Jurado, F. Camacho, G. Luzón, and J. M. Vicaria, "Kinetic models of activity for B-galactosidases: influence of $\mathrm{pH}$, ionic concentration and temperature," Enzyme and Microbial Technology, vol. 34, no. 1, pp. 33-40, 2004.

[20] H. Vila-Real, A. J. Alfaia, M. E. Rosa, A. R. Calado, and M. H. L. Ribeiro, "An innovative sol-gel naringinase bioencapsulation process for glycosides hydrolysis," Process Biochemistry, vol. 45, no. 6, pp. 841-850, 2010.

[21] D. Montgomery and R. Myers, Response Surface Methodology: Process and Product Optimization Using Designed Experiments, Wiley-Interscience, 2002.

[22] D. Norouzian, A. Hosseinzadeh, D. Nouri Inanlou, and N. Moazami, "Production and partial purification of naringinase by Penicillium decumbens PTCC 5248," World Journal of Microbiology and Biotechnology, vol. 16, no. 5, pp. 471-473, 2000.

[23] J. P. Henley and A. Sadana, "Categorization of enzyme deactivations using a series-type mechanism," Enzyme and Microbial Technology, vol. 7, no. 2, pp. 50-60, 1985.

[24] H. Y. Tsen, S. Y. Tsai, and G. K. Yu, "Fiber entrapment of naringinase from Penicillium sp. and application to fruit juice debittering," Journal of Fermentation and Bioengineering, vol. 67, no. 3, pp. 186-189, 1989.

[25] G. Ellenrieder and M. Daz, "Thermostabilization of naringinase from Penicillium decumbens by proteins in solution and immobilization on insoluble proteins," Biocatalysis and Biotransformation, vol. 14, no. 2, pp. 113-123, 1996.

[26] M. Gallego, F. Pinaga, D. Ramon, and S. Valles, "Purification and characterization of an alpha-L-Rhamnosidase from Aspergillus terreus of interest in winemaking," Journal Food Science, vol. 66, pp. 204-209, 2001.

[27] P. Manzanares, M. Orejas, E. Ibañez, S. Vallés, and D. Ramón, "Purification and characterization of an $\alpha$-L-rhamnosidase from Aspergillus nidulans," Letters in Applied Microbiology, vol. 31, no. 3, pp. 198-202, 2000.

[28] M. Mutter, G. Beldman, H. A. Schols, and A. G. J. Voragen, "Rhamnogalacturonan alpha-L-rhamnopyranohydrolase. A novel enzyme specific for the terminal nonreducing rhamnosyl unit in rhamnogalacturonan regions of pectin," Plant Physiology, vol. 106, no. 1, pp. 241-250, 1994.

[29] P. Manzanares, H. C. Van Den Broeck, L. H. De Graaff, and J. Visser, "Purification and Characterization of Two Different
$\alpha$-L-Rhamnosidases, RhaA and RhaB, from Aspergillus aculeatus," Applied and Environmental Microbiology, vol. 67, no. 5, pp. 2230-2234, 2001.

[30] F. Soria and G. Ellenrieder, "Thermal inactivation and product inhibition of Aspergillus terreus CECT $2663 \alpha$ L-rhamnosidase and their role on hydrolysis of naringin solutions," Bioscience, Biotechnology and Biochemistry, vol. 66, no. 7, pp. 1442-1449, 2002. 

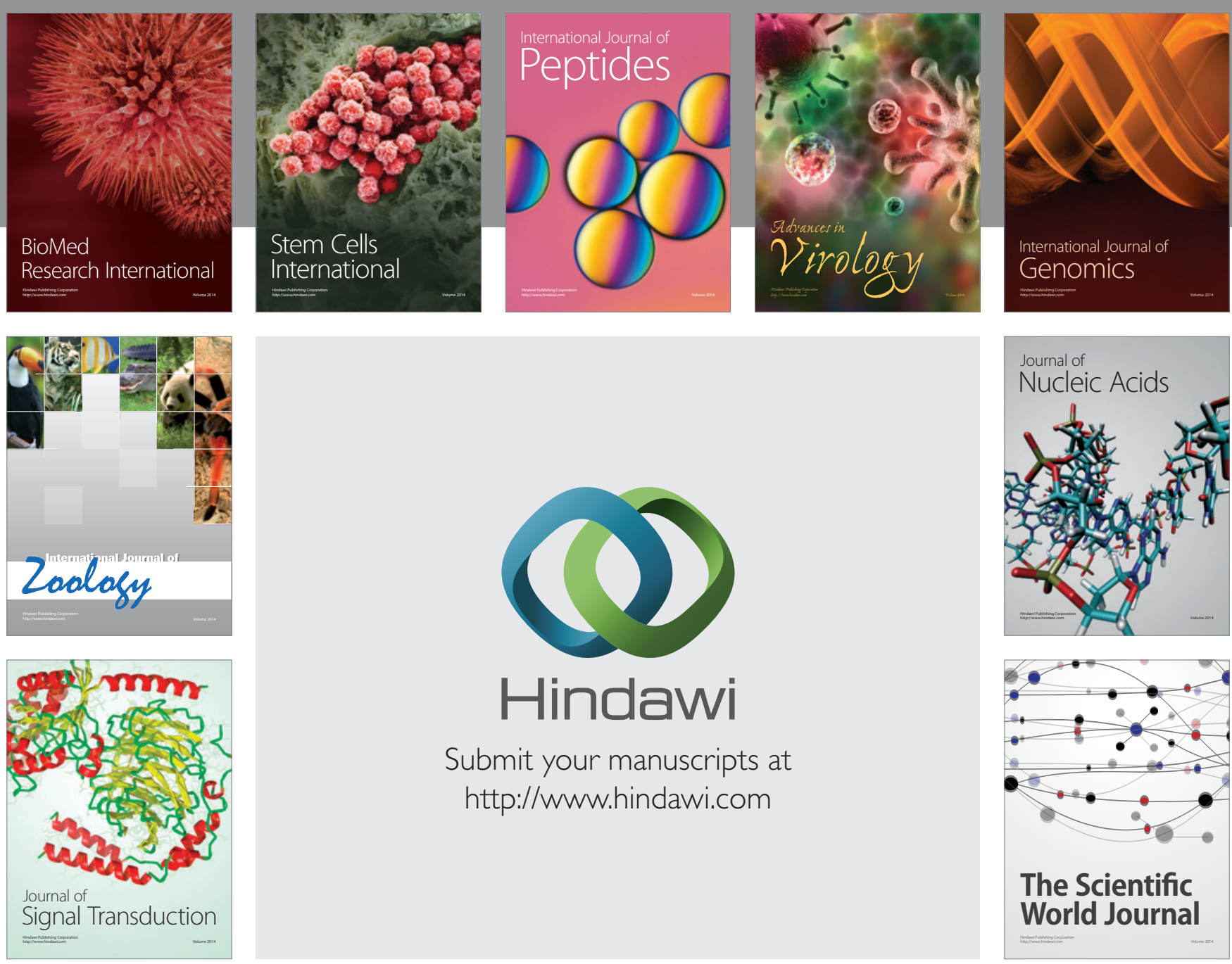

Submit your manuscripts at

http://www.hindawi.com
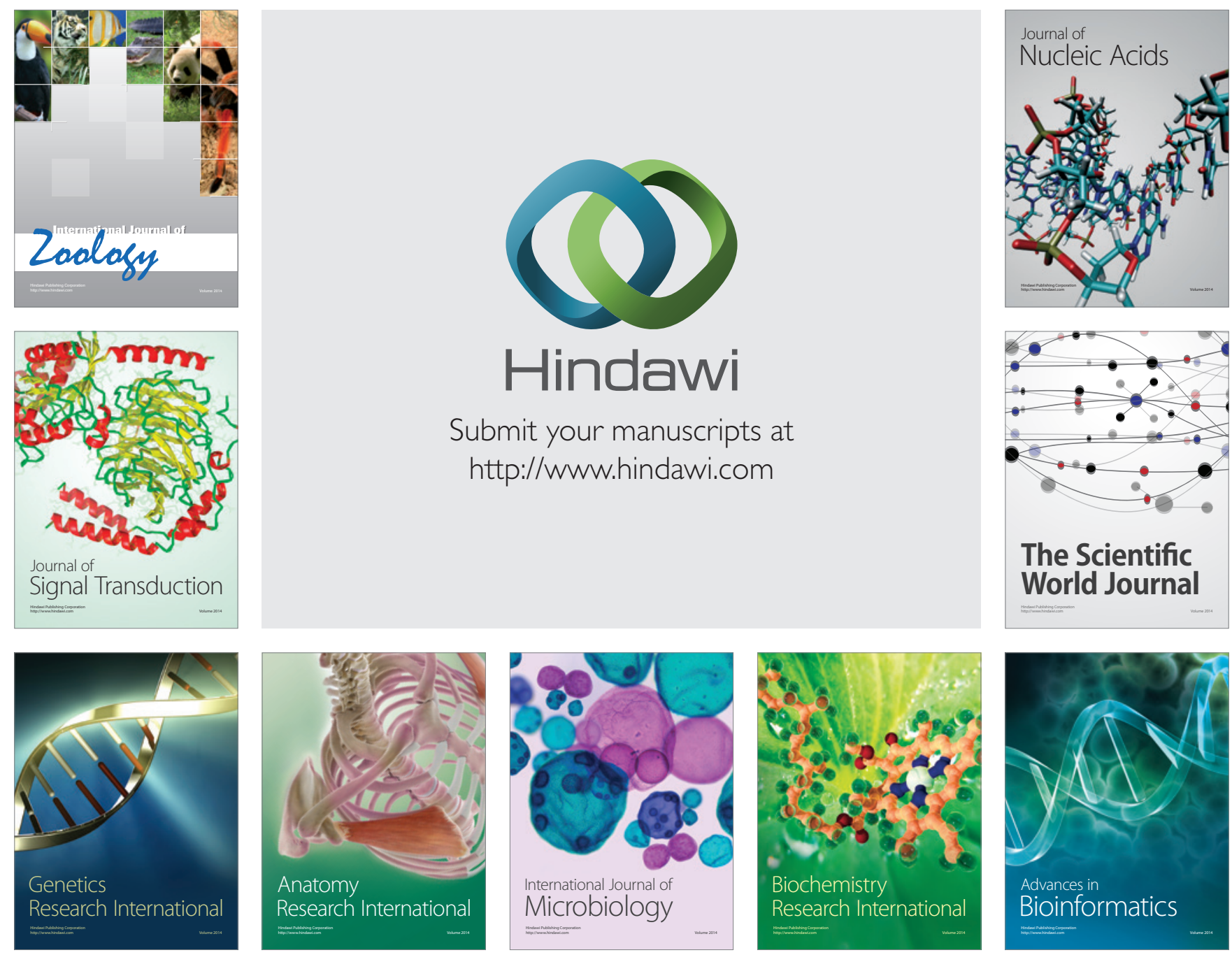

The Scientific World Journal
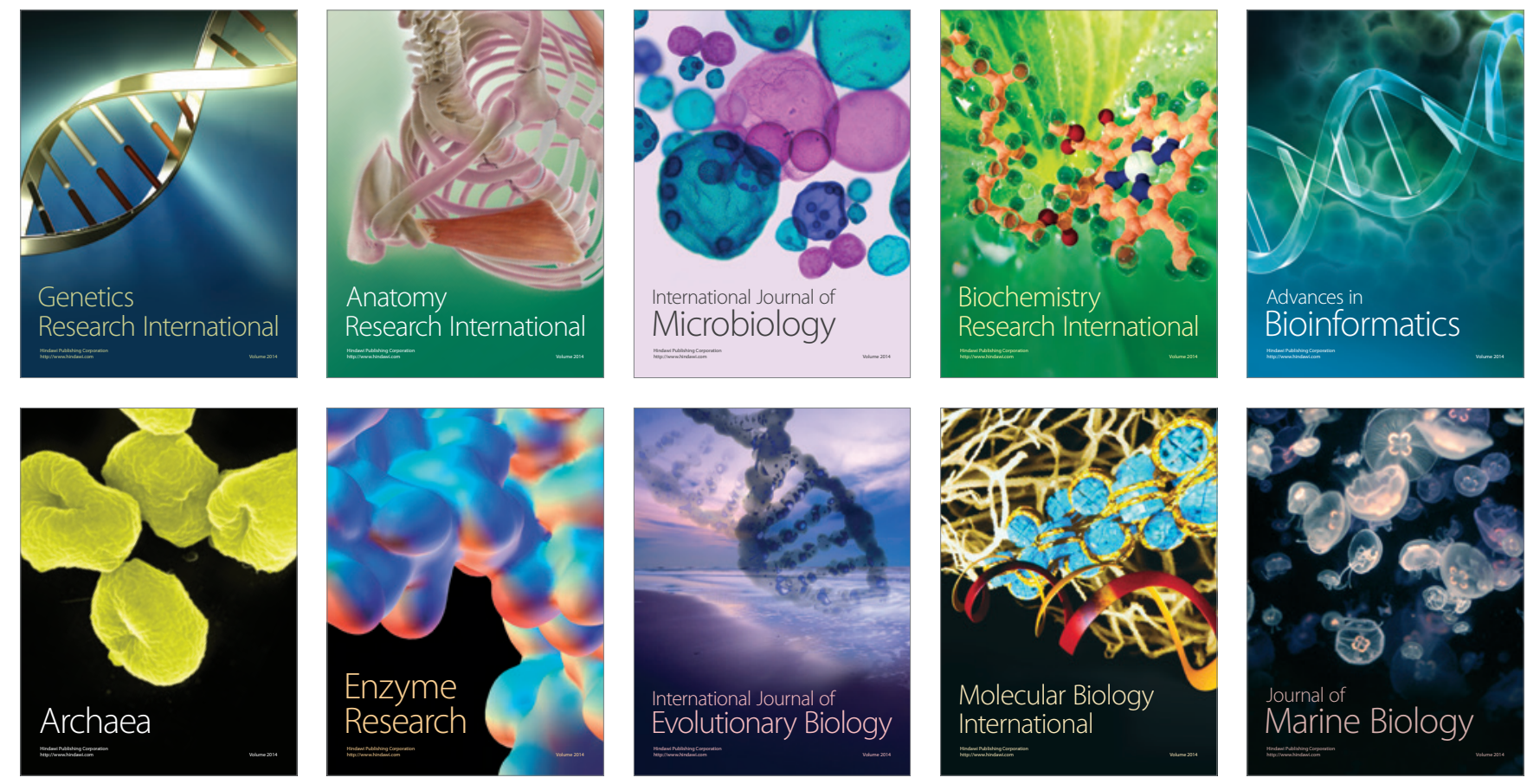